PERSPECTIVE

Excellent Hospital Care for All: Open and Operating 24/7

Hannah J. Wong, $P h D^{1,2}$ and Dante Morra, MD, MBA ${ }^{2,3,4}$

'Institute for Technology Assessment and Department of Imaging, Massachusetts General Hospital and Harvard Medical School, Boston, MA, USA; ${ }^{2}$ Centre for Innovation in Complex Care, University Health Network, Toronto, Ontario, Canada; ${ }^{3}$ Division of General Internal Medicine, Department of Medicine, University Health Network, University of Toronto, Toronto, Ontario, Canada; ${ }^{4}$ Toronto General Hospital, Toronto,

Ontario, Canada.

Nights and weekends are the times when most people are admitted to the hospital. They are also synonymous with reduced staffing levels and fewer specialized diagnostic, procedural, and treatment options. Indeed, there is increasing evidence suggesting that patient care is compromised during these times. Equally important is the inefficient use of capital investments during nights and weekends, and inappropriate utilization of hospital beds caused by poor weekend discharge flexibility. We believe that these findings should be of concern not just to hospital care providers, but across care settings and to the general public. In this perspective article, we highlight how our current office-hours system of running hospitals threatens the lives of our sickest, most vulnerable patients, describe solutions currently implemented in hospitals that may alleviate this disparity, and discuss challenges to wider scale implementation.

KEY WORDS: nights and weekend; hospital care; quality and safety; efficiency.

J Gen Intern Med 26(9):1050-2

DOI: $10.1007 /$ s1 1606-011-1715-8

(C) Society of General Internal Medicine 2011

$\mathrm{H}$ ospitals provide a safety net for people who need access to vital health care. This is especially true for those requiring care during nights and weekends, where traditional means of accessing health care are largely unavailable. In fact, nights and weekends are the times when most people are admitted to the hospital. Increasingly, however, there is evidence suggesting that patient care, especially for those with time-sensitive conditions, is compromised during these times and that the safety net in place leaves patients unnecessarily vulnerable. We believe that these findings should be of concern not just to hospital care providers, but across care settings and to the general public. In this perspective article, we highlight how our current office-hours system of running hospitals threatens the lives of our sickest, most vulnerable patients, describe solutions currently implemented in hospitals that may alleviate this disparity, and discuss challenges to wider scale implementation.

Received November 29, 2010

Revised March 22, 2011

Accepted March 24, 2011

Published online April 16, 2011

\section{CURRENT SITUATION}

For the majority of hospitals here in the United States and Canada, nights and weekends are synonymous with reduced staffing levels and fewer specialized diagnostic, procedural, and treatment options. Weekends pose a particularly challenging problem. They comprise an extended period of time with limited staffing, wide physician cross-coverage, and lack of resource-intensive services, yet they experience demands for care that are comparable to weekdays. This potentially long period of inactivity multiplies the risk of adverse events and sub-optimal patient care and outcomes. Indeed, a large body of research has shown that patients with timesensitive conditions like stroke, acute myocardial infarction, upper gastrointestinal bleeding, acute pulmonary embolism, and pneumonia are more likely to die if admitted to hospital on weekends compared to weekdays. ${ }^{1-3}$ Nights and weekends are also associated with less aggressive care ${ }^{4}$ higher rates of surgical complications ${ }^{5}$ and medical errors, ${ }^{6}$ and mortality from in-hospital cardiac arrest. ${ }^{7}$ Factors cited as contributing to this disparity include skeleton medical and nursing coverage, often exacerbated by less experience, supervision, and patient familiarity than their weekday counterparts. ${ }^{8,9}$ Limited specialized clinics, complex medical care, inter-professional expertise, and breakdowns in communication further compromise care during these times. ${ }^{10}$

\section{INNOVATIVE SOLUTIONS}

Just as the pace of research characterizing night/weekend care disparities has accelerated, there has also been an increase in the number of studies reporting no significant differences in care and outcomes during nights and weekends. These studies highlight potential workable solutions that remove the unnecessary variation in patient outcomes based on time of day and day of the week. In particular, studies that have evaluated round-the-clock 24/7 ICU and trauma staffing found no variability between arrival time and outcomes of care. ${ }^{11,12}$ In a recent study of a general medicine service that maintains the same staffing ratio on weekends as that on weekdays, researchers found that night or weekend admission was not associated with worse patient outcomes and suggested that consistent staffing, coordinated handoffs, and rotation schedules that protected against discontinuity may facilitate narrowing the gap in disparity. ${ }^{13}$ Moreover, in a study that evaluated policies to improve communication in surgical care, including resident-attending notification regarding routine weekend patient status and weekend patient visits by an attending, results showed significant reductions in potentially 
harmful communication breakdowns. ${ }^{14}$ Other studies have suggested centralization of resources within a hospital (e.g., Code Blue Teams ${ }^{15}$ ) and within a community (e.g., Trauma and Stroke centers ${ }^{16}$ ) to provide uniform, formalized, dependable staffing and resources in the face of capacity constraints. Collectively, these studies illustrate innovative staffing and process solutions that have had a positive effect on improving off-hours care. The applicability and practicality of these solutions need to be determined in other teaching, community, and small hospital settings. Nonetheless, to the best of our knowledge, no study has demonstrated that inconsistent staffing or resources are associated with better or comparable patient care and outcomes.

Investments in 24/7 care can also pay dividends in hospital efficiency. The reality for the hospital sector is that underutilization of capital investments during nights and weekends is a waste of expensive resources. Equally important is the inappropriate utilization of hospital beds caused by poor weekend discharge flexibility. As beds remain occupied by patients who could be safely discharged, the impact ripples throughout the hospital system, and clinical gridlock ensues in the Emergency Department (ED), ICU, and surgical services. The common response is a call for more beds. A more rational response is to first ensure that current operations are running as efficiently as possible so that existing resources deliver their maximum output. For hospitals, this translates to standardizing care processes so that weekends run exactly as they do on weekdays, scheduling of imaging procedures and interventions during nights and weekends ${ }^{17}$, and consistently discharging patients every day of the week. ${ }^{18}$ Such strategies are likely to serve both inpatient and outpatient needs, improve equipment return on investment, shorten queues for service, reduce unnecessary length of stay, and alleviate ED congestion. A recent simulation study found that smoothing inpatient discharges over the course of the week reduced ED length of stay and the number of ED beds occupied by patients waiting for ward transfer by $\sim 30 \% .{ }^{19}$

\section{CHALLENGES TO WIDE-SCALE IMPLEMENTATION}

Even as research clearly demonstrates the disparity in off-hours care and provides potential solutions to narrow this gap, change has been slow and disappointing. Challenges to wider scale implementation of 24/7 hospital solutions are broad and include costs, provider preferences, and availability of services outside of the hospital. First, the upfront costs of maintaining weekday staffing levels during nights and weekends are not trivial. Indeed, a common strategy for hospitals trying to contain operating costs is to reduce staffing levels. However, the longer term consequences of these actions have not proven cost-effective. Staff reductions have been shown to negatively impact the safety and quality of hospital care, and as a result, drive the costs per patient discharge up. ${ }^{20}$ And while there is a dearth of quantified evidence of the costs and utility of 24/7 care, research is beginning to fill in the gaps. In a recent study that analyzed the savings-cost ratio of increased ICU nurse-to-patient ratios on prevention of adverse events, it was found that even the most expensive staffing model generated net savings from avoided patient adverse events. ${ }^{21}$ Specifically, savings from prevented adverse events ranged from $\$ 2.2$ million to $\$ 13.2$ million, while nurse staffing costs for the same time frame were $\$ 1.36$ million. Additionally, in a 2-year prospective study to evaluate the introduction of night-shift coverage to provide continuous 24 -h on-site critical care specialists, the study authors found that in addition to reductions in ICU complication rates and hospital length of stay, there were improved processes of care and staff satisfaction. ${ }^{22}$

Second, provider feasibility of $24 / 7$ care is tempered by conflicting views. On the one hand, clinicians are increasingly expressing quality of life as a priority, making night and weekend coverage more unpopular. ${ }^{23,24}$ On the other hand, high-quality patient care is a major if not the most important factor in increasing job satisfaction among nurses and physicians. ${ }^{25-27}$ Therefore, future cost-utility analyses should also incorporate considerations of provider preferences, especially in our current environment of workforce shortages. It is clear that we need to implement and evaluate new models that would encourage providers to reorganize so that they have incentives to take responsibility for off-hour patient outcomes and more efficient utilization of precious resources.

Another critical consideration for hospitals looking to improve weekend care is the disparity that exists outside in the community. Even with adequate hospital staffing and resources to prepare and coordinate weekend hospital discharge, hospitals rely on community resources (home care, transportation, professional services) and post-acute care facilities (long-term care, rehabilitation, palliative care) for the safe transition from hospital to home. Currently, few health care providers along the care continuum have the resource capacity to accept new patients on weekends. ${ }^{28}$

Finally, the tendency for hospitals and health care sectors in general to wait for the financial sector to impose incentives or penalties as a means to change is worth acknowledging. Currently, there is neither reward for reducing nor punishment for maintaining the disparities in off-hours care. While linking improvements in off-hours care and outcomes to reimbursements may be a promising way forward, we believe hospitals need to take the lead in acknowledging and seriously addressing the safety, quality, and efficiency gaps in night and weekend care.

\section{CONCLUSION}

Night and weekend disparities in hospital care represent a legitimate and challenging issue. Hospitals, like other emergency industries including firefighting and police services, need to function identically on weekends as on weekdays; staffing and service levels need to be indistinguishable 7 days a week. For nights, we advocate for full staffing in areas where early intervention is crucial for positive outcomes, including the ED, ICU, and trauma services. Additional investments in 24-h staffing and resources for other hospital services can be prioritized using critical event and cost-benefit analyses.

Now is the time for providers and policy makers alike to take up the challenge and raise off-hours care to the forefront as a target area for innovative change and reform. If we really are committed to providing excellent, safe, efficient quality care for all, our hospitals need to be open and operating 24/7.

Contributors: None

Funders: None

Prior Presentations: None

Conflict of interest: None disclosed. 
Corresponding Author: Dante Morra, MD, MBA; Toronto General Hospital, 200 Elizabeth Street, EN 14-218, Toronto, Ontario M5G 2C4, Canada (e-mail: dante.morra@utoronto.ca).

\section{REFERENCES}

1. Aujesky D, Jimenez D, Mor MK, Geng M, Fine MJ, Ibrahim SA Weekend versus weekday admission and mortality after acute pulmonary embolism. Circulation. 2009;119(7):962-8.

2. Kostis WJ, Demissie K, Marcella SW, Shao YH, Wilson AC, Moreyra AE. Weekend versus weekday admission and mortality from myocardial infarction. N Engl J Med. 2007;356(11):1099-109.

3. Bell CM, Redelmeier DA. Mortality among patients admitted to hospitals on weekends as compared with weekdays. N Engl J Med. 2001;345(9):663-8.

4. Kazley AS, Hillman DG, Johnston KC, Simpson KN. Hospital care for patients experiencing weekend vs weekday stroke: a comparison of quality and aggressiveness of care. Arch Neurol. 2010;67(1):39-44.

5. Bendavid E, Kaganova Y, Needleman J, Gruenberg L, Weissman JS. Complication rates on weekends and weekdays in US hospitals. Am J Med. 2007;120(5):422-8.

6. Miller AD, Piro CC, Rudisill CN, Bookstaver PB, Bair JD, Bennett CL. Nighttime and weekend medication error rates in an inpatient pediatric population. Ann Pharmacother. 2010;44(11):1739-46.

7. Peberdy MA, Ornato JP, Larkin GL, et al. Survival from in-hospital cardiac arrest during nights and weekends. Jama. 2008;299(7):785-92.

8. Cram P, Hillis SL, Barnett M, Rosenthal GE. Effects of weekend admission and hospital teaching status on in-hospital mortality. Am J Med. 2004;117(3):151-7.

9. Shojania KG, Fletcher KE, Saint S. Graduate medical education and patient safety: a busy-and occasionally hazardous-intersection. Ann Intern Med. 2006;145(8):592-8.

10. Shulkin DJ. Assessing hospital safety on nights and weekends: the SWAN tool. J Patient Saf. 2009;5(2):75-8.

11. Arabi Y, Alshimemeri A, Taher S. Weekend and weeknight admissions have the same outcome of weekday admissions to an intensive care unit with onsite intensivist coverage. Crit Care Med. 2006;34(3):605-11.

12. Carr BG, Jenkins P, Branas C, et al. Does the trauma system protect against the weekend effect? In: Eastern Association for the Surgery of Trauma 23rd Annual Scientific Assembly. Phoenix, AZ: 2010.

13. Khanna R, Wachsberg K, Marouni A, Feinglass J, Williams MV, Wayne DB. The association between night or weekend admission and hospitalization-relevant patient outcomes. J Hosp Med. 2011;6(1):10-4.
14. Arriaga AF, Elbardissi AW, Regenbogen SE, et al. A policy-based intervention for the reduction of communication breakdowns in inpatient surgical care: results from a harvard surgical safety collaborative. Ann Surg. 2011.

15. Gureshi SA, Ahern T, O'Shea R, Hatch L, Henderson SO. A standardized code blue team eliminates variable survival from in-hospital cardiac arrest. J Emerg Med. 2011.

16. Carr BG, Nance ML. Access to pediatric trauma care: alignment of providers and health systems. Curr Opin Pediatr. 2010;22(3):326-31.

17. Lee LH, Swensen SJ, Gorman CA, Moore RR, Wood DL. Optimizing weekend availability for sophisticated tests and procedures in a large hospital. Am J Manag Care. 2005; 11(9):553-8.

18. Wong $\mathbf{H}$, Wu RC, Tomlinson $\mathbf{G}$, et al. How much do operational processes affect hospital inpatient discharge rates? J Public Health (Oxf). 2009;31(4):546-53.

19. Wong HJ, Wu RC, Caesar M, Abrams H, Morra D. Smoothing inpatient discharges decreases emergency department congestion: a system dynamics simulation model. Emerg Med J. 2010;27(8):593-8.

20. Sovie MD, Jawad AF. Hospital restructuring and its impact on outcomes: nursing staff regulations are premature. J Nurs Adm. 2001;31 (12):588-600

21. Rothschild JM, Bates DW, Franz C, Soukup JR, Kaushal R. The costs and savings associated with prevention of adverse events by critical care nurses. J Crit Care. 2009;24(3):471. e1-7.

22. Gajic O, Afessa B, Hanson AC, et al. Effect of 24-hour mandatory versus on-demand critical care specialist presence on quality of care and family and provider satisfaction in the intensive care unit of a teaching hospital. Crit Care Med. 2008;36(1):36-44.

23. Iglehart JK. Grassroots activism and the pursuit of an expanded physician supply. N Engl J Med. 2008;358(16):1741-9.

24. Moseley A, Jeffers L, Paterson J. The retention of the older nursing workforce: a literature review exploring factors which influence the retention and turnover of older nurses. Contemp Nurse. 2008;30(1):4656.

25. Utriainen K, Kyngas $\mathbf{H}$. Hospital nurses' job satisfaction: a literature review. J Nurs Manag. 2009;17(8):1002-10.

26. Hamilton P, Eschiti VS, Hernandez K, Neill D. Differences between weekend and weekday nurse work environments and patient outcomes: a focus group approach to model testing. J Perinat Neonatal Nurs. 2007;21(4):331-41.

27. Wallace JE, Lemaire JB, Ghali WA. Physician wellness: a missing quality indicator. Lancet. 2009;374(9702):1714-21.

28. Greenwald JL, Denham CR, Jack BW. The hospital discharge: a review of a high risk care transition with highlights of a reengineered discharge process. J Patient Saf. 2007;3(2):97-106. 